\title{
AERIAL SUPPRESSION PENETRATING AN AXIALLY SYMMETRIC AND UPRIGHT BUOYANT WILDFIRE PLUME
}

\author{
RICKARD HANSEN \\ The University of Queensland, Australia.
}

\begin{abstract}
An analysis was conducted on when aerial suppression through direct attack using a helicopter could be ineffective due to a high heat release rate of the wildfire. The analysis consisted of a numerical estimate and where the results were compared with existing operational thresholds on aerial wildfire suppression. It was found that up to a heat release rate of $10000 \mathrm{~kW}$, practically all droplet paths effectively penetrated the plume region. At heat release rates of 12500 and $23000 \mathrm{~kW}$, only the path at an angle to the centreline effectively penetrated the plume region. The calculated results of the analysis were compared with suppression thresholds and found to correspond well in the vertical trajectory case. The findings of the paper could serve as starting point for the development of decision support for aerial wildfire suppression.
\end{abstract}

Keywords: aerial, fire suppression, plume, water, wildfire.

\section{INTRODUCTION}

During the suppression of a wildfire a direct attack [1] - suppression action aimed directly at the flaming edge, in order to slow or stop the spread of the flaming edge - with water may be conducted through aerial suppression. The direct attack is usually performed on smaller and low-intensity fires as the type of attack will have a limited effect on high intensity fires [1]. When conducting a direct attack, parts of the drop will encounter the rising fire plume as opposed to an indirect attack where the drop will be positioned at a distance from the flaming edge.

As opposed to fires in buildings where small droplets will have a large extinguishing effect on the fire, the droplets during aerial suppression will have to be sufficiently large to penetrate parts of the fire plume, reaching the fuel or the flames to have an extinguishing effect as the complete vaporization of smaller droplets before reaching the flames or fuel will have no effect on the fire. Fire extinguishment during aerial suppression of a wildfire can be performed in one or several of the following approaches:

- Applying droplets on fuel adjacent to the flaming edge. This will decrease the amount of heat from the flame radiation available for the pyrolysis process, as some of the flame radiation heat will be used for evaporating the extinguishing agent. This may delay or even prevent the ignition of the fuel surface.

- Applying droplets on burning fuel surfaces. This will cool the fuel surface and decrease the pyrolysis rate, possibly to the extent where the fire is extinguished.

- Applying droplets into the flames. This will decrease the flame radiation towards the fuel surface and slow down the pyrolysis rate.

A considerable number of studies have been conducted on the release of the suppressant from the aircraft, the breakup of the load, the formation of droplets and the ground deposition of the drop. Andersen et al. [2-4] presented studies on the dynamics affecting the extinguishing agent during an aerial drop. George and Blakely [5], as well as Stechishen [6], performed 
experiments on the ground deposition of aerial retardant drops. Swanson and Helvig [7, 8], as well as Swanson et al. [9-11], developed a model for predicting ground deposition. Newstead and Lieskovsky [12] studied the canopy interception of the drop. Amorim [13] presented an operational air drop model, allowing for a near real-time simulation of aerial drops. Recently, a number of new studies have been focused on the effectiveness of wildfire suppression [14-16]. However, no study has been conducted on the interaction with the rising fire plume.

The aim of this paper is to investigate when aerial suppression through a direct attack with water could possibly be ineffective due to a high heat release rate of the wildfire. What droplet diameters achieve suppression effects on the flaming edge, i.e. decreases the flame radiation and slows down the pyrolysis rate? Aerial suppression without any or very limited suppression effects will only be a waste of valuable suppressants that could be applied elsewhere. This paper is limited to the cases where helicopters are used, when gravity is the driving force during the discharge of the suppressant and to the case of axially symmetric and upright fire plumes.

\section{AERIAL APPLICATION}

During aerial application of an extinguishing agent, several different stages are run through. Initially, the extinguishing agent is released from the aircraft, followed by the deformation and breakup of the droplets and finally the deposition of the drop on the ground.

The breakup of the droplets composes of two different types: the primary breakup where the load is broken up into larger droplets and the secondary breakup where the droplets are broken up, forming a spray cloud. The breakup of the load will largely determine the droplet velocity, the size and the size distribution of the droplets [13]. The breakup, in turn, will be determined by the viscosity of the suppressant, the velocity and direction of the aircraft and the drop height.

In the analysis, the focus will be on the phase where the interaction between the falling droplets and the fire plume flow takes place. The focus will also be on the occurrence of a secondary breakup of the droplets as this may occur while the droplets are penetrating the fire plume. The primary breakup is assumed to occur momentarily upon the release of the drop and thus droplets are assumed to occur at the very discharge of the water load. The ground deposition stage is unaccounted for as we are primarily interested in whether plume penetration will take place or not. Neither is the issue of canopy influence on the load deposition accounted for in the analysis. During the analysis, the drag coefficient was calculated using the Reynolds number as a limit and assuming a spherical droplet.

\section{PLUME MODEL AND THE PENETRATION OF THE FIRE PLUME}

The plume model by Baum and McCaffrey [17] was used in this study as this plume model describes the flow fields of a single and unconfined plume, where the plume remains axially symmetric and upright. The plume model was developed to describe large conflagrations. The plume model is aimed at describing the low level flows (i.e. a few hundred metres above the fire source) and is not valid for cases where the local winds or stratification largely affect the plume. Therefore, the flow of the plume is assumed to dominate over any horizontal wind flow and only the flow of the plume was accounted for in the calculations of the secondary breakup. The plume model accounts for the winds induced by the fire. The plume model is divided vertically into three regions: starting from the bottom is the continuous flame region, where the anchored flame sheets to the fuel bed can be found. Above, the intermittent region 
can be found where irregular patches of flames can be found. Further up, the plume region where only hot gases and no visible flames can be found. The plume model by Baum and McCaffrey was selected as the boundary where the visible flames cease to exist could be effectively pinpointed for the various heat release rates. The general appearance of the fire plume can be seen in Fig. 1 together with the droplet paths used in the analysis.

For the plume region (directly following upon the intermittent region where irregular patches of flames can be found), the following centreline correlations apply [17]:

$$
\begin{gathered}
\mathrm{U}^{*}=3.64 \cdot\left(\mathrm{z}^{*}\right)^{-1 / 3} \cdot \\
\mathrm{T}^{*}=8.41 \cdot\left(\mathrm{z}^{*}\right)^{-5 / 3} \cdot \\
\mathrm{z}^{*}=\mathrm{z} \cdot\left(\frac{\dot{\mathrm{Q}}_{\mathrm{c}}}{\rho_{\mathrm{a}} \cdot \mathrm{c}_{\mathrm{p}} \cdot \mathrm{T}_{\mathrm{a}} \cdot \mathrm{g}^{1 / 2}}\right)^{-2 / 5} . \\
\mathrm{U}=\mathrm{U}^{*} \cdot\left(\frac{\dot{\mathrm{Q}}_{\mathrm{c}} \cdot \mathrm{g}^{2}}{\rho_{\mathrm{a}} \cdot \mathrm{c}_{\mathrm{p}} \cdot \mathrm{T}_{\mathrm{a}}}\right)^{1 / 5} . \\
\mathrm{T}=\mathrm{T}_{\mathrm{a}}+\mathrm{T}_{\mathrm{a}} \cdot \mathrm{T}^{*}
\end{gathered}
$$

where $\mathrm{U}^{*}$ is the dimensionless centreline plume velocity, $\mathrm{U}$ is the centreline plume velocity $[\mathrm{m} / \mathrm{s}], \mathrm{z}^{*}$ is the dimensionless vertical distance from fire source, $\mathrm{T}^{*}$ is the dimensionless centreline plume temperature, $\mathrm{T}$ is the centreline plume temperature $[\mathrm{K}], \mathrm{z}$ is the vertical distance from fire source $[\mathrm{m}], \dot{Q}_{c}$ is the convective heat release rate $[\mathrm{kW}], \rho_{\mathrm{a}}$ is the ambient density $\left[\mathrm{kg} / \mathrm{m}^{3}\right], \mathrm{c}_{\mathrm{p}}$ is the specific heat of air $[\mathrm{kJ} / \mathrm{kg} \cdot \mathrm{K}], \mathrm{T}_{\mathrm{a}}$ is the ambient air temperature $[\mathrm{K}]$ and $\mathrm{g}$ is the acceleration of gravity $\left[\mathrm{m} / \mathrm{s}^{2}\right]$.

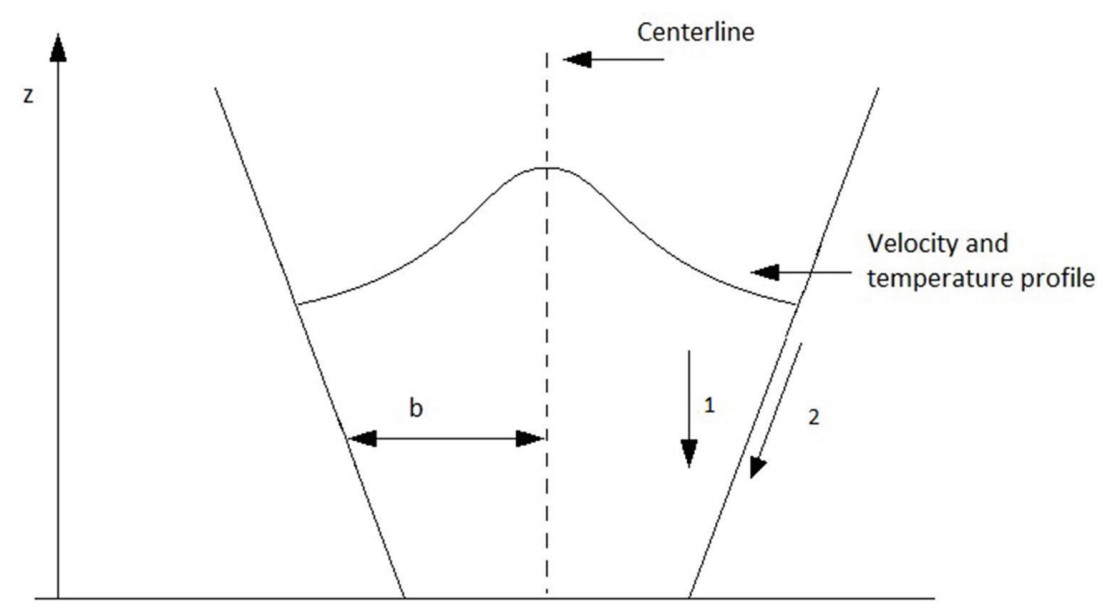

Figure 1: The appearance of the fire plume. Droplet paths: 1 - vertical, plume half-width distance; 2 - at an angle to the centreline, plume half-width distance. 
The convective heat release rate was assumed at $0.73 \cdot \dot{Q}$ in the calculations [18]. Assuming a Gaussian radial distribution for the vertical velocity [17]:

$$
\mathrm{u}(\mathrm{r})=U(z) \cdot e^{-\left(\frac{r}{b}\right)^{2}} .
$$

where $\mathrm{u}$ is the plume velocity $[\mathrm{m} / \mathrm{s}], \mathrm{r}$ is the radial distance from the plume centreline $[\mathrm{m}]$ and $\mathrm{b}$ is the plume half-width [m].

For the temperature [19]:

$$
\frac{\mathrm{T}(\mathrm{r})-\mathrm{T}_{\mathrm{a}}}{\mathrm{T}-\mathrm{T}_{\mathrm{a}}}=e^{-0.91 \cdot\left(\frac{r}{b}\right)^{2}} .
$$

The thermal plume half-width is calculated depending upon whether the plume at the height in question is regarded as a weak plume $\left(\rho \approx \rho_{a}\right)$ or a strong plume. Weak plume [19]:

$$
\mathrm{b}_{\mathrm{w}}=0.13 \cdot z \text {. }
$$

Strong plume [19]:

$$
\mathrm{b}_{\mathrm{s}}=0.13 \cdot \mathrm{z} \cdot\left(\frac{\rho_{\mathrm{a}}}{\rho}\right)^{1 / 2} .
$$

In the calculations the thermal plume half-width was assumed to be equal to the velocity plume half-width.

The plume region will have to be penetrated by the falling droplet to cause any effect on the ongoing combustion process. Even water droplets aimed at the area directly adjacent to the flaming edge may have to at least partially penetrate the plume region due to the increasing plume radius with height above the fire source.

The flame height correlation by McCaffrey [20]:

$$
\mathrm{L}_{\mathrm{f}}=2.3 \cdot D_{h} \cdot\left(\frac{\dot{Q}}{\rho_{a} \cdot c_{p} \cdot T_{a} \cdot g^{1 / 2} \cdot D^{5 / 2}}\right)^{2 / 5},
$$

which is valid for:

$$
0.2 \leq\left(\frac{\dot{Q}}{\rho_{a} \cdot c_{p} \cdot T_{a} \cdot g^{1 / 2} \cdot D^{5 / 2}}\right) \leq 1.1 .
$$

where $L_{f}$ is the flame height $[\mathrm{m}], \mathrm{D}_{\mathrm{h}}$ is the hydraulic diameter $[\mathrm{m}], \dot{\mathrm{Q}}$ is the heat release rate $[\mathrm{kW}]$ and $\mathrm{D}$ is the fire diameter $[\mathrm{m}]$.

\subsection{Penetration of the fire plume}

During fire suppression on the ground the water stream will not have to travel through the fire plume as the application is performed sideways. During aerial application on a wildfire, some of the load will travel through the fire plume to reach the flames and the fuel directly adjacent to the flames. Droplets travelling through the fire plume will pass through the hot gases of the 
fire plume before reaching the flames of the plume. Assuming a spherically shaped container filled with water underneath the aircraft, the initial velocity of the droplets is calculated as the velocity of a single particle falling through a height h under the influence of gravity:

$$
\mathrm{u}_{\mathrm{w}}=\sqrt{2 \cdot g \cdot h} \text {. }
$$

where $\mathrm{u}_{\mathrm{w}}$ is the droplet velocity $[\mathrm{m} / \mathrm{s}]$ and $\mathrm{h}$ is the height $[\mathrm{m}]$.

The height was set equal to the radius of the sphere, resulting in an average initial velocity of the droplets being discharged from the container. The volume of the sphere was set to $1 \mathrm{~m}^{3}$ as a starting value, resulting in an average discharge velocity of the suppressant of $u_{w}=3.4$ $\mathrm{m} / \mathrm{s}$ in the calculations. The volume of $1 \mathrm{~m}^{3}$ was selected as it is a fairly common size of a bambi bucket. The influence of the size of the container - resulting in other initial average discharge velocities - is further analyzed in the discussion section.

The subsequent velocity increase of the droplet can be expressed by [21]:

$$
\begin{gathered}
\frac{\mathrm{du}_{\mathrm{w}}}{\mathrm{dt}}=-\left(\frac{18 \cdot \mu_{g} \cdot C_{d} \cdot R e_{r e l}}{24 \cdot \rho_{w} \cdot d^{2}}\right) \cdot\left(u-u_{w}\right)+g . \\
R e_{r e l}=\rho_{g} \cdot d \cdot \frac{\left|u_{w}-u\right|}{\mu_{g}} .
\end{gathered}
$$

where $t$ is the time [s], $\mu_{g}$ is the molecular viscosity of the plume $[\mathrm{kg} /(\mathrm{s} \cdot \mathrm{m})], \mathrm{C}_{\mathrm{d}}$ is the drag coefficient, $\operatorname{Re}_{\text {rel }}$ is the relative Reynolds number, $\rho_{\mathrm{w}}$ is the water droplet density $\left[\mathrm{kg} / \mathrm{m}^{3}\right], \mathrm{d}$ is the droplet diameter $[\mathrm{m}]$ and $\rho_{\mathrm{g}}$ is the plume gas density $\left[\mathrm{kg} / \mathrm{m}^{3}\right]$.

A free falling water droplet will not accelerate indefinitely, but will eventually attain a maximum velocity termed a terminal velocity. The terminal velocity of a water droplet in a gravity regime is expressed by [22]:

$$
\mathrm{u}_{\mathrm{t}}=\left(\frac{4 \cdot \rho_{w} \cdot d \cdot g}{3 \cdot \rho_{a} \cdot C_{d}}\right)^{1 / 2} .
$$

where the drag coefficient is calculated using [22]:

$$
\begin{gathered}
\mathrm{C}_{\mathrm{d}}=\frac{24}{\operatorname{Re}} \cdot\left(1+\frac{\operatorname{Re} e^{2 / 3}}{6}\right) \operatorname{Re}<1000 . \\
\mathrm{C}_{\mathrm{d}}=0.424 \operatorname{Re} \geq 1000 .
\end{gathered}
$$

Above calculated velocity increase must be checked against the terminal velocity of the water droplet as the terminal velocity will represent an upper boundary.

Equation (15) is valid in a gravity regime and well suited as this paper is limited to the cases where gravity represents the driving force.

A water droplet travelling through the fire plume due to the force of gravity must obtain a terminal velocity that exceeds the plume velocity of the plume region to cause any effect at all on the combustion taking place. 
To attain sufficiently high terminal velocities, the droplets will have to be large. But the situation is further complicated by two phenomena: larger droplets are unstable and will break up into smaller droplets, and droplets falling through a hot fire plume may be completely or partially vaporized and result in smaller droplets that are unable to penetrate the plume.

\subsection{Primary and secondary breakup}

The distribution of the droplet sizes following the primary breakup is of interest as the distribution will represent a key factor when describing the actual fraction of droplets eventually penetrating the plume region. A report by Van Meter and George [23] contained the resulting droplet distribution after the primary break up of a water load in a wind tunnel with a longitudinal velocity of $64.4 \mathrm{~km} / \mathrm{h}$. The presented droplet distribution with a peak value for 1.4 $\mathrm{mm}$ droplets was used in the calculations and analysis. The impact of the aircraft velocity on the resulting droplet distribution is discussed in this paper.

The secondary breakup will occur when the drag pressure exceeds the surface tension pressure of the droplet. Condition for secondary breakup to occur:

$$
\mathrm{C}_{\mathrm{d}} \cdot \frac{\pi \cdot d^{2}}{4} \cdot 0.5 \cdot \rho_{g} \cdot u^{2}=\pi \cdot d \cdot \sigma .
$$

where $\sigma$ is the surface tension $[\mathrm{mN} / \mathrm{m}]$.

The equation above can be rearranged:

$$
\frac{\rho_{\mathrm{g}} \cdot \mathrm{u}^{2} \cdot \mathrm{d}}{\sigma}=\frac{8}{C_{d}}=W e .
$$

where We is the Weber number.

Experimental data shows that a critical Weber number of approximately 11 is required for secondary breakup to occur [24].

The drag coefficient will be dependent on the Reynolds number and expressed by [25]:

$$
\begin{gathered}
\mathrm{C}_{\mathrm{d}}=18.5 \cdot R e_{r e l}^{-0.6} R e_{r e l}<600 . \\
\mathrm{C}_{\mathrm{d}}=0.44 R e_{r e l}>600 .
\end{gathered}
$$

The secondary breakup will consist of one of the two breakup regimes: bag breakup or shear breakup, depending on the relative velocity (which is accounted for in the Weber number). The type of breakup regime will determine the resulting droplet distribution. Bag breakup will occur for Weber numbers lower than 100 and shear breakup for Weber numbers of 100 or higher [26]. The Weber numbers resulting from the ensuing calculations were lower than 100 in all cases.

Jain et al. [24] presented the droplet distribution after a secondary break up at moderate Weber numbers where only a very small fraction of the resulting droplets was found to be $10 \%$ or larger of the initial droplet size. Only a very small fraction of the resulting droplets was found in the calculations to be undeflected at the lower heat release rates. Thus a droplet found to undergo secondary break up was assumed to be deflected following upon the break up. 


\subsection{Vaporization of droplets}

For the ensuing set of equations the following assumptions were made:

- droplet evaporation is quasi-steady

- droplet temperature is uniform and below the boiling point

- mass fraction of vapor at the droplet surface is determined by liquid-vapor equilibrium at the droplet temperature.

The evaporating droplet diameter as a function of time can be expressed by [27]:

$$
\frac{\mathrm{dd}^{2}}{\mathrm{dt}}=-\frac{8 \cdot \rho_{g} \cdot D_{\text {Water-Air }}}{\rho_{w}} \cdot \ln \left(1+B_{Y}\right) .
$$

where $\mathrm{D}_{\text {Water-Air }}$ is the binary diffusivity of water and air and $\mathrm{B}_{\mathrm{Y}}$ is the dimensionless transfer number.

In the calculations the binary diffusivity of water and air was applied, air being the principal component in the mixture of air and gases from the wildfire. The binary diffusivity of water and air is a function of the temperature and in the ensuing analysis diffusivity coefficients from Tamimi et al. [28] were used. Linear interpolation was applied for intermediate temperatures. Equation of the dimensionless transfer number [27]:

$$
\mathrm{B}_{\mathrm{Y}}=\frac{Y_{\text {water }, s}-Y_{\text {water }, \infty}}{1-Y_{\text {water }, s}} .
$$

where $Y_{\text {water }, s}$. is the water mass fraction at the droplet surface and $\mathrm{Y}_{\text {water, } \infty}$ is the water mass fraction very far from the water droplet surface.

The water mass fraction very far from the water droplet surface was set to zero in the calculations. Equations of the water mass fraction at the droplet surface and the mole fraction of water [27]:

$$
\begin{gathered}
Y_{\text {water }, s}=\chi_{\text {water }} \cdot \frac{M W_{\text {water }}}{\chi_{\text {water }} \cdot M W_{\text {water }}+\left(1-\chi_{\text {water }}\right) \cdot M W_{\text {air }}} . \\
\frac{P_{\text {sat }}}{P}=e^{\left(\frac{h_{f g}}{\left(8315 / M W_{\text {water }}\right)} \cdot\left(\frac{1}{T_{\text {surface }}}-\frac{1}{T_{\text {boil }}}\right)\right)}=\chi_{\text {water }} .
\end{gathered}
$$

where $\chi_{\text {water }}$ is the mole fraction of water, $M W_{\text {water }}$ is the molecular weight of water $[\mathrm{kg} /$ $\mathrm{kmol}], M W_{\text {air }}$ is the molecular weight of air $[\mathrm{kg} / \mathrm{kmol}], P_{\text {sat }}$ is the saturation pressure [Pa], $P$ is the pressure $[\mathrm{Pa}], h_{f g}$ is the heat of vaporization at $1 \mathrm{~atm}[\mathrm{~J} / \mathrm{kg}], T_{\text {surface }}$ is the surface droplet temperature $[\mathrm{K}]$ and $T_{\text {boil }}$ is the boiling point $[\mathrm{K}]$.

The heat of vaporization at 1 atm of water was set to $2.257 \cdot 10^{6} \mathrm{~J} / \mathrm{kg}$, the boiling point of water was set to $373 \mathrm{~K}$ and the droplet surface temperature was assumed to be equal to the droplet temperature (see assumption above).

The change in droplet temperature can be expressed as [21]:

$$
\frac{d T_{\text {droplet }}}{d t}=\frac{6 \cdot k_{g} \cdot g \cdot\left(2+0.6 \cdot \operatorname{Re}^{1 / 2} \cdot \operatorname{Pr}^{1 / 3}\right) \cdot\left(T-T_{\text {droplet }}\right)}{\rho_{w} \cdot d^{2} \cdot c_{p, \text { water }}} .
$$


where $T_{\text {droplet }}$ is the droplet temperature $[\mathrm{K}], k_{g}$ is the thermal conductivity of the plume gases $[\mathrm{W} / \mathrm{m} \cdot \mathrm{K}], \operatorname{Pr}$ is the Prandtl number and $c_{p \text {,water }}$ is the specific heat of water $[\mathrm{kJ} / \mathrm{kg} \cdot \mathrm{K}]$.

\section{METHOD}

A model was set up to calculate the potential penetration of the plume region of falling droplets, applying the various listed expressions above. Microsoft Office Excel spreadsheet software was used during the calculation of the numerical model. A time step of $0.1 \mathrm{~s}$ was used in the calculations.

During the calculations, the following parameters were varied:

- Droplet diameter (range: 0.1-2.1 mm).

- Drop height (droplets were released from 10 to $80 \mathrm{~m}$ above the base of the fire source).

- Drop path.

- Heat release rate of the fire.

The droplets were released from the different heights including the following paths (see also Fig. 1 for clarification):

- Vertically and in parallel with the centreline, where the droplet - after having penetrated the plume region - will be at the plume half-width position.

- At an angle to the centreline and following the plume half-width distance to the centreline.

The paths were chosen as they can both be found at the very outskirts of the fire plume, where light smoke will be encountered.

The applied heat release rates and corresponding plume parameters can be found in Table 1 . The heat release rates $10000 \mathrm{~kW}, 12500 \mathrm{~kW}$ and $23000 \mathrm{~kW}$ were chosen as the corresponding

Table 1: The heat release rates of the calculations and corresponding plume parameters.

\begin{tabular}{ccccc}
\hline $\begin{array}{c}\text { Heat } \\
\text { release rate } \\
(\mathbf{k W})\end{array}$ & $\begin{array}{c}\text { Convective heat } \\
\text { release rate (kW) }\end{array}$ & $\begin{array}{c}\text { Continuous } \\
\text { flame region }(\mathbf{m})\end{array}$ & $\begin{array}{c}\text { Intermittent } \\
\text { region }(\mathbf{m})\end{array}$ & $\begin{array}{c}\text { Plume region } \\
(\mathbf{m})\end{array}$ \\
\hline 1000 & 730 & $\mathrm{z}<1.2$ & $1.2 \leq \mathrm{z} \leq 2.7$ & $\mathrm{z}>2.7$ \\
5000 & 3650 & $\mathrm{z}<2.2$ & $2.2 \leq \mathrm{z} \leq 5.3$ & $\mathrm{z}>5.3$ \\
10000 & 7300 & $\mathrm{z}<2.9$ & $2.9 \leq \mathrm{z} \leq 7.0$ & $\mathrm{z}>7.0$ \\
12500 & 9125 & $\mathrm{z}<3.1$ & $3.1 \leq \mathrm{z} \leq 7.6$ & $\mathrm{z}>7.6$ \\
23000 & 16790 & $\mathrm{z}<4.0$ & $4.0 \leq \mathrm{z} \leq 9.8$ & $\mathrm{z}>9.8$ \\
Heat release & Plume temp. at 10 & Plume temp. at & Plume temp. at & Plume temp. at \\
rate $(\mathrm{kW})$ & $\mathrm{m}$ height (K) & $20 \mathrm{~m}$ height $(\mathrm{K})$ & $30 \mathrm{~m}$ height $(\mathrm{K})$ & $40 \mathrm{~m}$ height $(\mathrm{K})$ \\
1000 & 328 & 305 & 299 & 297 \\
5000 & 373 & 326 & 311 & 304 \\
10000 & 397 & 341 & 320 & 311 \\
12500 & 406 & 347 & 324 & 313 \\
23000 & 426 & 365 & 337 & 322 \\
\hline
\end{tabular}




\begin{tabular}{ccccc}
\hline $\begin{array}{c}\text { Heat release } \\
\text { rate }(\mathrm{kW})\end{array}$ & $\begin{array}{c}\text { Plume temp. at 50 } \\
\text { m height }(\mathrm{K})\end{array}$ & $\begin{array}{c}\text { Plume temp. at } \\
\text { 60 m height }(\mathrm{K})\end{array}$ & $\begin{array}{c}\text { Plume temp. at } \\
70 \mathrm{~m} \text { height }(\mathrm{K})\end{array}$ & $\begin{array}{c}\text { Plume temp. at } \\
80 \mathrm{~m} \text { height }(\mathrm{K})\end{array}$ \\
1000 & 294 & 294 & 294 & 294 \\
5000 & 296 & 295 & 295 & 294 \\
10000 & 298 & 297 & 296 & 295 \\
12500 & 299 & 297 & 296 & 296 \\
23000 & 302 & 300 & 298 & 297 \\
\hline
\end{tabular}

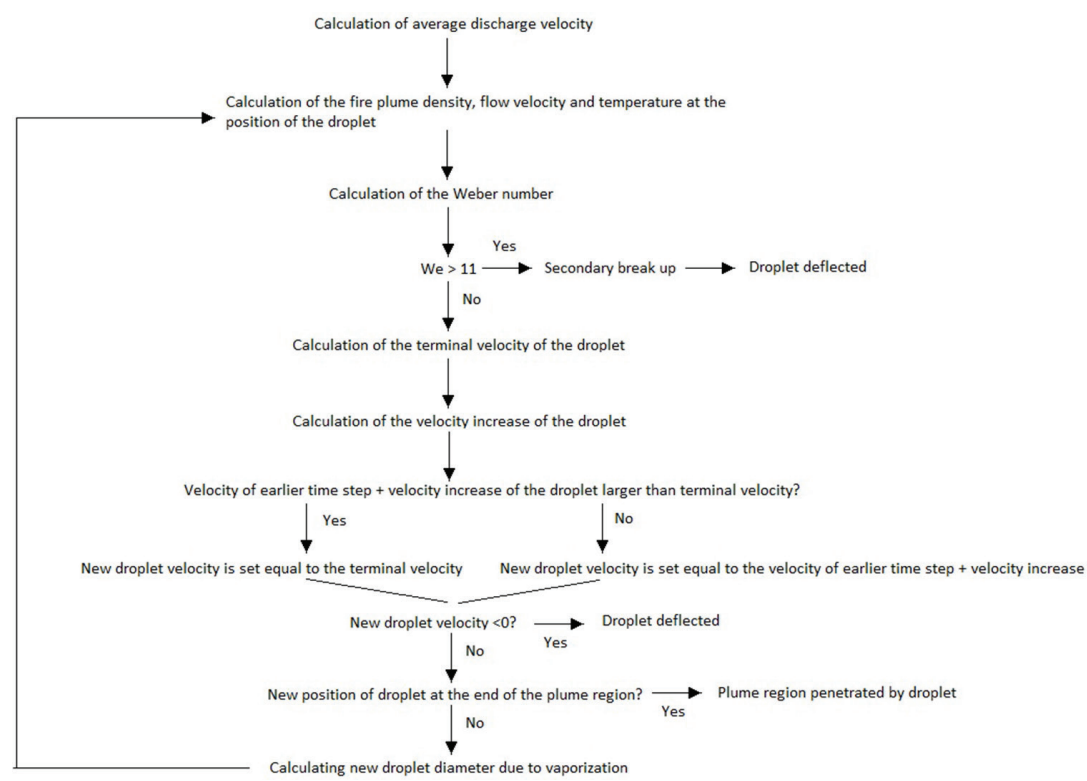

Figure 2: Flowchart indicating the calculation procedure of each time step of the simulations.

continuous flame regions were around $3 \mathrm{~m}$ and $4 \mathrm{~m}$, which would be of interest during the validation of the calculations. The plume temperatures are given as the temperatures at plume half-width.

The extent of the various regions were calculated using the following conditions [17]:

- Continuous flame region: $0<z^{*}<1.32$

- Intermittent region: $1.32<z^{*}<3.30$

- Plume region: $3.30<z^{*}$

Figure 2 displays the calculation procedure for each time step, where the heat release rate of the fire, drop height, horizontal distance from centreline and droplet diameter after primary break up were varied.

\section{RESULTS AND DISCUSSION}

Below, the calculated results are listed as well as a number of discussion sections where influential parameters are discussed with respect to the results. 
Table 2: The calculated results for the $1000 \mathrm{~kW}$ fire scenario.

\begin{tabular}{|c|c|c|c|c|c|}
\hline Path & $\begin{array}{l}\text { Drop } \\
\text { height } \\
(\mathbf{m})\end{array}$ & $\begin{array}{l}\text { Droplet } \\
\text { diameter } \\
\text { range } \\
(\mathbf{m m})\end{array}$ & Path & $\begin{array}{l}\text { Drop } \\
\text { height } \\
(\mathbf{m})\end{array}$ & $\begin{array}{c}\text { Droplet } \\
\text { diameter } \\
\text { range } \\
(\mathbf{m m})\end{array}$ \\
\hline \multirow{8}{*}{$\begin{array}{l}\text { Vertically and at a } \\
\text { plume half-width } \\
\text { distance }\end{array}$} & 10 & $0.7-1.5$ & \multirow{8}{*}{$\begin{array}{l}\text { At an angle to the } \\
\text { centreline and } \\
\text { following the plume } \\
\text { half-width distance }\end{array}$} & 10 & $0.4-1.3$ \\
\hline & 20 & $0.7-1.5$ & & 20 & $0.4-1.2$ \\
\hline & 30 & $0.6-1.5$ & & 30 & $0.4-1.1$ \\
\hline & 40 & $0.6-1.4$ & & 40 & $0.4-1.1$ \\
\hline & 50 & $0.6-1.3$ & & 50 & $0.5-1.1$ \\
\hline & 60 & $0.6-1.3$ & & 60 & $0.6-1.1$ \\
\hline & 70 & $0.6-1.3$ & & 70 & $0.6-1.1$ \\
\hline & 80 & $0.6-1.3$ & & 80 & $0.6-1.0$ \\
\hline
\end{tabular}

The calculation results for the different fires can be seen in Tables 2-6, where the successful penetration of the plume region is presented as the droplet diameter range where penetration takes place. Droplets with diameters below the range were deflected and diameters above the range underwent secondary break up with ensuing deflection.

With increasing heat release rate and drop height, the droplet range generally becomes more narrow. This is due to the increased plume flow velocity with increasing heat release rate and the increased risk of secondary break up with increased drop height.

In most cases the lower boundary of the droplet range is lower for the trajectory at an angle to the centreline compared with the vertical trajectory. This is explained by the decrease in plume flow velocities with increased distance from the centreline. A decrease in the plume flow velocity will decrease the risk of smaller droplets being deflected.

For both paths, the lower boundary raises for the lower heat release rates and then levels off.

Table 3: The calculated results for the $5000 \mathrm{~kW}$ fire scenario.

\begin{tabular}{cccccc}
\hline Path & $\begin{array}{c}\text { Drop } \\
\text { height } \\
(\mathbf{m})\end{array}$ & $\begin{array}{c}\text { Droplet } \\
\text { diameter } \\
\text { range } \\
(\mathbf{m m})\end{array}$ & Path & $\begin{array}{c}\text { cop } \\
\text { height } \\
(\mathbf{m})\end{array}$ & $\begin{array}{c}\text { Droplet } \\
\text { diameter } \\
\text { range } \\
(\mathbf{m m})\end{array}$ \\
\hline & 10 & $0.7-1.9$ & & 10 & $0.5-1.9$ \\
Vertically and at a & 40 & $0.8-1.9$ & & 20 & $0.5-1.5$ \\
plume half-width & 50 & $0.8-1.9$ & At an angle to the & 30 & $0.6-1.4$ \\
distance & 50 & $0.9-1.7$ & centreline and & 40 & $0.7-1.3$ \\
& 60 & $1.0-1.7$ & following the plume & 50 & $0.7-1.3$ \\
& 70 & $1.1-1.6$ & & 60 & $0.7-1.2$ \\
& 80 & $1.1-1.6$ & & 70 & $0.8-1.2$ \\
\hline
\end{tabular}


Table 4: The calculated results for the $10000 \mathrm{~kW}$ fire scenario.

\begin{tabular}{cccccc}
\hline Path & $\begin{array}{c}\text { Drop } \\
\text { height } \\
(\mathbf{m})\end{array}$ & $\begin{array}{c}\text { Droplet } \\
\text { diameter } \\
\text { range } \\
(\mathbf{m m})\end{array}$ & Path & $\begin{array}{c}\text { Drop } \\
\text { height } \\
(\mathbf{m})\end{array}$ & $\begin{array}{c}\text { Droplet } \\
\text { diameter } \\
\text { range } \\
(\mathbf{m m})\end{array}$ \\
\hline & 10 & $0.7-1.8$ & & 10 & $0.7-2.1$ \\
Vertically and at a & 40 & $0.7-1.4$ & & 20 & $0.6-1.8$ \\
plume half-width & 50 & $0.7-1.3$ & At an angle to the & 30 & $0.7-1.6$ \\
distance & 50 & $0.7-1.4$ & centreline and & 40 & $0.9-1.5$ \\
& 60 & $1.0-1.4$ & following the plume & 50 & $0.9-1.4$ \\
& 70 & $1.1-1.4$ & & 60 & $0.9-1.4$ \\
& 80 & $1.1-1.4$ & & 70 & $1.0-1.3$ \\
\hline
\end{tabular}

In most cases the upper boundary will increase with increased heat release rate for the same drop height. The increase is most noticeable when comparing the upper boundaries of the $1000 \mathrm{~kW}$ fire plume with the $5000 \mathrm{~kW}$ case. With increasing heat release rate, the plume density will decrease and result in decreasing risk of secondary break up. For the higher heat release rates the increase in the upper boundary starts to level off.

Generally, more extensive penetration of the fire plume can be seen in the case of the trajectory at an angle to the centreline.

The $5000 \mathrm{~kW}$ plume temperature at $10 \mathrm{~m}$ drop height and the $12500 \mathrm{~kW}$ plume temperature at the $20 \mathrm{~m}$ height are close to or above the boiling point of water (see Table 1), rendering drops from these positions questionable.

For the vertical trajectory at the $12500 \mathrm{~kW}$ fire plume, no droplet diameter penetrated the plume region at drop heights higher than $50 \mathrm{~m}$. For the $23000 \mathrm{~kW}$ case, virtually no droplet diameter penetrated the plume for the vertical trajectory.

Table 5: The calculated results for the $12500 \mathrm{~kW}$ fire scenario.

\begin{tabular}{cccccc}
\hline Path & $\begin{array}{c}\text { Drop } \\
\text { height } \\
(\mathbf{m})\end{array}$ & $\begin{array}{c}\text { Droplet } \\
\text { diameter } \\
\text { range } \\
(\mathbf{m m})\end{array}$ & Path & $\begin{array}{c}\text { Drop } \\
\text { height } \\
(\mathbf{m})\end{array}$ & $\begin{array}{c}\text { Droplet } \\
\text { diameter } \\
\text { range } \\
(\mathbf{m m})\end{array}$ \\
\hline & 10 & $0.7-2.0$ & & 10 & $0.7-2.1$ \\
Vertically and at a & 40 & $0.9-1.3$ & & 20 & $0.6-1.7$ \\
plume half-width & 50 & $0.8-1.2$ & At an angle to the & 30 & $0.7-1.6$ \\
distance & 50 & $0.9-1.2$ & centreline and & 40 & $0.9-1.5$ \\
& 60 & - & following the plume & 50 & $0.9-1.5$ \\
& 70 & - & & 60 & $0.9-1.4$ \\
& 80 & - & & 70 & $0.9-1.4$ \\
\hline
\end{tabular}


Table 6: The calculated results for the $23000 \mathrm{~kW}$ fire scenario.

\begin{tabular}{cccccc}
\hline Path & $\begin{array}{c}\text { Drop } \\
\text { height } \\
(\mathbf{m})\end{array}$ & $\begin{array}{c}\text { Droplet } \\
\text { diameter } \\
\text { range (mm) }\end{array}$ & Path & $\begin{array}{c}\text { Drop } \\
\text { height } \\
(\mathbf{m})\end{array}$ & $\begin{array}{c}\text { Droplet } \\
\text { diameter } \\
\text { range (mm) }\end{array}$ \\
\hline 10 & $\begin{array}{c}\text { End of plume } \\
\text { region coin- } \\
\text { cides with drop } \\
\text { height }\end{array}$ & & 10 & $\begin{array}{c}\text { End of plume } \\
\text { region coin- } \\
\text { cides with } \\
\text { drop height }\end{array}$ \\
Vertically and at & 20 & $1.0-1.3$ & $\begin{array}{c}\text { At an angle to } \\
\text { the centreline }\end{array}$ & 20 & $0.8-1.5$ \\
width distance & 30 & - & $\begin{array}{c}\text { and following the } \\
\text { plume half-width }\end{array}$ & 40 & $0.9-1.3$ \\
& 40 & - & distance & 50 & $0.9-1.3$ \\
& 60 & - & & 60 & $1.0-1.3$ \\
& 70 & - & & 70 & $1.0-1.3$ \\
& 80 & - & & 80 & $1.1-1.3$ \\
\hline
\end{tabular}

Comparing the ranges found in Tables $2-6$ with the droplet distribution found in report by Van Meter and George [23], a considerable part of the total droplet distribution penetrated the plume region of the $1000 \mathrm{~kW}$ and $5000 \mathrm{~kW}$ cases except for the higher drop heights of the path at an angle to the centreline (the $10 \mathrm{~m}$ drop height in the $5000 \mathrm{~kW}$ case was unaccounted for due to high plume temperatures). For the $10000 \mathrm{~kW}$ case both paths effectively penetrated the plume region for all drop heights. Regarding the $12500 \mathrm{~kW}$ and $23000 \mathrm{~kW}$ cases only the path at an angle to the centreline effectively penetrated the plume region at all drop heights (the $20 \mathrm{~m}$ drop height of the vertical path at an angle to the centreline and at a half-width distance is not considered for due to high plume temperatures).

\subsection{Comparison of results with operational thresholds}

The following operational suppression thresholds were applied when comparing with the calculated results:

- Equipment like retardant aircraft can be effective: a flame length of 4-8 feet [29].

- Single retardant drops ineffective - due to heavy spotting across the line - at approximately $2000 \mathrm{~kW} / \mathrm{m}$ in mixed species Eucalypt forest [30].

- No useful retarding effect for forest fires exceeding $5000 \mathrm{~kW} / \mathrm{m}[30]$.

The flame lengths of the heat release rates listed above were calculated by applying the following expression by Thomas [31] - suitable for fires with higher heat release rates:

$$
L_{f}=0.0266 \cdot I^{2 / 3}
$$

where $I$ is the heat release rate per unit length fireline $[\mathrm{kW} / \mathrm{m}]$.

A heat release rate of $2000 \mathrm{~kW} / \mathrm{m}$ would result in a flame length of approximately $4.2 \mathrm{~m}$ and $5000 \mathrm{~kW} / \mathrm{m}$ a flame length of approximately $7.8 \mathrm{~m}$ applying eqn. (27). It is unclear 
whether the flame length of eqn. (27) and the flame length of 4-8 feet are continuous or intermittent flame lengths. But if assuming intermittent flame lengths, the 4-8 feet flame length would be approximately equivalent to a $1000 \mathrm{~kW}$ fire, the $2000 \mathrm{~kW} / \mathrm{m}$ would be approximately equivalent to a $12500 \mathrm{~kW}$ fire and the $5000 \mathrm{~kW} / \mathrm{m}$ to a $23000 \mathrm{~kW}$ fire. Comparing the cases where the plume region was effectively penetrated with the suppression thresholds above, the calculated results of the vertical trajectory were found to correspond well with the suppression thresholds. The results of the trajectory at an angle to the centreline were found to predict too extensive droplet ranges penetrating the plume region for the $23000 \mathrm{~kW}$ case.

It is unclear whether the above listed threshold of Andrews \& Rothermel [29] also includes water drops and should therefore be used with caution. The number of operational thresholds is limited when it comes to water drops, which is unfortunate with respect to future studies.

\subsection{Discharge velocity}

A larger or smaller container underneath the aircraft would result in a different discharge velocity. Spherically shaped containers of $0.5 \mathrm{~m}^{3}$ and $2 \mathrm{~m}^{3}$, would result in average discharge velocities of $3.1 \mathrm{~m} / \mathrm{s}$ and $3.9 \mathrm{~m} / \mathrm{s}$, respectively. The average discharge velocities were applied in the $5000 \mathrm{~kW}$ fire calculations to investigate the influence on the resulting droplet diameter range. A discharge velocity of $3.1 \mathrm{~m} / \mathrm{s}$ had minor or negligible influence on the lower boundary of the diameter range but the upper boundary lowered when comparing with the $3.4 \mathrm{~m} / \mathrm{s}$ case. Secondary break up occurred for lower droplet diameters, narrowing the droplet diameter range. A discharge velocity of $3.9 \mathrm{~m} / \mathrm{s}$ caused a raise of the upper boundary, therefore expanding the droplet diameter range. A larger container, resulting in a higher discharge velocity would lead to a higher chance of plume penetration.

\subsection{Characteristics of the falling droplets}

The drag coefficient of the single droplet was calculated assuming a spherical droplet and an incompressible fluid. In reality the individual droplets will deform - increasing the frontal area facing the upward plume flow - when falling through the fire plume. This will result in an increase in the drag coefficient. Due to the heavy load of the water drop, the density of the water droplet may not initially be assumed to have a constant density. The density of the individual droplets will be higher, decreasing the drag coefficient.

The extent of the two different and counteracting phenomena will have to be investigated further.

\subsection{Aircraft velocity}

The resulting droplet size distribution following on the primary break up of the load will be determined by, for example, the horizontal velocity of the aircraft. An increase in the horizontal velocity will decrease the average droplet diameter [32] and the risk of secondary break up occurring, but the risk of deflection will on the other hand increase depending on the position of the drop. The velocity of the aircraft will, therefore, have to be chosen depending on whether secondary break up or deflection should be avoided.

Drops made at an angle to the centreline will not be hovering drops and will, therefore, reduce the average diameter of droplets, which should be considered when making the drop.

During the analysis, the applied distribution of the droplet sizes was based on experiments in a wind tunnel with a longitudinal velocity of $64.4 \mathrm{~km} / \mathrm{h}$ [23]. A case with a different 
velocity will result in a different average droplet diameter and droplet size distribution. However, the ranges of droplet diameters in Tables 2-6 would not change with the aircraft velocity. Still, adjustments to the conclusions on the effective penetration of the plume region would be necessary with a different aircraft velocity.

\subsection{Vaporization of droplets}

During the calculations, the vaporization of the falling droplet with a resulting decrease in droplet diameter was calculated but found to have a negligible effect on the outcome of the drop cases. The decrease in droplet diameter was too small to have any effects. Even though the drop height, as well as the time falling through the fire plume, was considerable, it was only at the very end of the plume region that the temperatures of the fire plume reached temperature levels that would imply rapid vaporization. But the high fire plume temperatures in this region will also imply a lower fire plume density which in turn will cause an increase in the droplet velocity, decreasing the time the droplet is exposed to higher temperatures. In addition, reaching the lower regions of the plume, the droplet has generally undergone an acceleration phase and attained the terminal velocity which will lead to a shorter time period exposed to higher temperatures. Possibly, smaller droplets with lower velocities that could have undergone noticeable vaporization in the lower parts of the plume had already been deflected at an early stage.

Even though the falling droplets may not fully vaporize, a partial vaporization may still influence the fire plume. Following on the primary breakup the load and the formation of droplets, the partial vaporization will result in the formation of water vapour. The water vapour will mix with the rising plume flow and interact with the plume flow as a cooler, negatively buoyant gas phase.

Additional calculations were performed using a time increment of $0.01 \mathrm{~s}$ in order to investigate whether the vaporization process had not been properly modelled due to too long time increments. Still, the results showed negligible effects on the droplet diameters.

\subsection{Types of fuel}

In the calculations the convective heat release rate was assumed at $0.73 \cdot \dot{Q}$ [18], which is valid for Pinus Pinaster as the convective fraction will vary depending on the fuel. In the same publication the convective fraction for Erica Arborea is given as 0.80, which is approximately $10 \%$ higher. Applying a convective fraction of 0.80 in a number of drop scenarios resulted in negligible or very small changes to the droplet diameter ranges.

\subsection{Horizontal distance from the centreline}

For higher drop heights and higher heat release rates, an increasing distance from the centreline will decrease the risk of deflection for the smaller droplets, but the risk of a secondary break up will on the other hand increase with increased distance.

Considering only the horizontal distance to the centreline, if larger droplets are desired the drop should be made closer to the centreline. If smaller droplets are desired, the drop should be made farther away from the centreline.

Larger droplets penetrating the plume region will lead to droplets reaching farther into the intermittent region, which is highly desirable. 
With increasing heat release rate, eventually, only the outer parts of the plume will be an option.

\subsection{Drop height}

The drop height will influence the risk of secondary break up of larger droplets as well as the risk of deflection of smaller droplets. The risk of a secondary break up as well as droplet deflection will increase with increased drop height. If considering only the drop height, the drop height should be as low as possible.

\subsection{Drops at an angle versus vertical drops}

The drops made at an angle to the centreline generally led to successful and effective penetration at higher heat release rates compared with the vertical path. At lower heat release rates the drops made at an angle displayed an increased risk of secondary break up with increasing drop height due to higher plume densities. At higher heat release rates, the risk of secondary break up was reduced for the trajectory made at an angle to the centreline. The risk of deflection is lower at lower heat release rates for the trajectory at an angle to the centreline, due to lower plume flow velocities.

If larger droplets are desired at a fire with lower heat release rate, the drop should be made applying a vertical trajectory. At higher heat release rates the drop should be made applying a trajectory at an angle to the centreline.

The path at an angle to the centreline will not be straight paths as the gravity will bend it, making the calculated path ideal but not realistic. A trajectory following exactly the half plume width will be even less realistic. Nevertheless, a path at an angle will encounter a different and more favourable plume density and flow gradients compared with a vertical path, increasing the likelihood of successful penetration of the plume region.

\subsection{Sensitivity analysis - time step}

A sensitivity analysis was conducted with respect to the time step employed in the calculations. A time step of $0.05 \mathrm{~s}$ was applied and found to have negligible or minor effects (less than $1 \%$ ) on the droplet diameter ranges compared with the $0.1 \mathrm{~s}$ results.

\subsection{Plume model}

This paper is based on a very specific plume model, i.e. an axially symmetric and buoyant fire plume. A wildfire will in many cases have a linear shape rather than a circular shape. Still, the linearly shaped fire front could be regarded as being dominated by one or more highly intensive circular sources resulting in a number of axially symmetric fire plumes [33]. Nevertheless, the plume temperatures and plume flows of a linearly shaped fire may be overestimated if applying a plume model for a circularly fire. Further studies should include other plume models as well as corresponding fire experiments in order to increase the applicability of the presented model.

This paper is based on a number of assumptions connected with the fire. Further work could include various shapes of fire areas and the wind affecting the fire plume. Further refining the model and increasing its applicability. 
The presented model could serve as a starting point for a decision tool when theoretically finding the optimal drop for a specific fire scenario. Being used as a pre-planning tool for aerial wildfire suppression, optimizing the use of the extinguishing agent. Furthermore, the presented model could with further refinements be included in an operational air drop model, supplementing the existing parts of the model.

\section{CONCLUSIONS}

The water droplet penetration of an axially symmetric and upright wildfire plume was analysed involving a numerical estimate. The focus has been on the potential penetration of the plume region of various paths and fires at different heat release rates. It was found that:

- Up to a heat release rate of $10000 \mathrm{~kW}$ more or less all droplet paths effectively penetrated the plume region. Except the higher drop heights of the path at an angle to the centreline for the $1000 \mathrm{~kW}$ and $5000 \mathrm{~kW}$ cases.

- For the $12500 \mathrm{~kW}$ and $23000 \mathrm{~kW}$ cases only the path at an angle to the centreline effectively penetrated the plume region at all drop heights.

- The calculated results were compared with existing operational thresholds and found to correspond with the suppression thresholds well in the case of the vertical trajectory but not the trajectory at an angle to the centreline.

- The trajectory at an angle to the centreline and following the plume half width should be regarded as an highly ideal trajectory but not a realistic one. Still, any drop made at an angle to the centreline generally led to a more frequent penetration at higher heat release rates compared with the vertical paths.

- The vaporization of the falling droplets was found to be negligible and cause an insignificant effect on the outcome.

- A larger container - resulting in a higher discharge velocity and a decreased risk of secondary break up - would lead to a higher chance of plume penetration.

- The drop height will influence the risk of secondary break up of larger droplets as well as the risk of deflection of smaller droplets.

The findings of the analysis and the presented model could after refinements - as a number of simplifying assumptions were made which limit the present application - serve as decision support for aerial wildfire suppression, optimizing the use of the extinguishing agent. A suitable trajectory, drop height, distance from the centreline and container size could be selected depending on the heat release rate of the fire. Further research is needed with respect to various shapes of fire areas, the wind affecting the fire plume, other fire plume models, other droplet shapes and the performance of fire experiments.

\section{REFERENCES}

[1] Plucinski, M., Gould, J., McCarthy, G. \& Hollis, J., The Effectiveness and Efficiency of Aerial Firefighting in Australia, Part 1. Bushfire CRC Technical Report Number A0701, 2007.

[2] Andersen, W.H., Brown, R.E., Kato, K.G. \& Louie, N.A., Investigation of Rheological Properties of Aerial-Delivered Fire Retardant - Final Report. USDA Forest Service, Intermountain Research Station, Report 8990-04, 1974.

[3] Andersen, W.H., Brown, R.E., Louie, N.A., Blatz, P.J. \& Burchfield, J.A., Investigation of Rheological Properties of Aerial-Delivered Fire Retardant Extended Study - Final Report. USDA Forest Service, Intermountain Research Station, Report 8990-05, 1974. 
[4] Andersen, W.H., Brown, R.E., Louie, N.A., Kato, K.G., Burchfield, J.A., Dalby, J.D. \& Zernow, L., Correlation of Rheological Properties of Liquid Fire Retardant With Aerially Delivered Performance - Final Report. USDA Forest Service, Intermountain Research Station, Report 8990-08, 1976.

[5] George, C.W. \& Blakely, A.D., An Evaluation of The Drop Characteristics and Ground Distribution Patterns Of Forest Fire Retardants. Research paper INT-134, USDA Forest Service, Ogden, 1973.

[6] Stechishen, E., CL-215 Air Tanker Modifications Improve Drop Pattern. Information report FF-X-61, Forest Fire Institute, Ottawa, 1976.

[7] Swanson, D.H., \& Helvig, T.N., High-altitude retardant drop mechanization study. Honeywell Inc., Government and Aeronautical Products Division, Final Report, vol. 1, contract 26-2888, 1973.

[8] Swanson, D.H., \& Helvig, T.N., Extended high-altitude retardant drop mechanization study. Honeywell Inc., Government and Aeronautical Products Division, Final Report, contract 26-2888, 1974.

[9] Swanson, D.H., Luedecke, A.D., Helvig, T.N. \& Parduhn, F.J., Development of User Guidelines for Selected Retardant Aircraft. Final report, contract 26-3332. Honeywell Inc., Government and Aeronautical Products Division, 1975.

[10] Swanson, D.H., Luedecke, A.D., Helvig, T.N. \& Parduhn, F.J., Supplement to Development of User Guidelines for Selected Retardant Aircraft. Honeywell Inc., Government and Aeronautical Products Division, Final report, contract 26-3332, 1977.

[11] Swanson, D.H., Luedecke, A.D. \& Helvig, T.N., Experimental Tank and Gating System (ETAGS). Honeywell Inc., Government and Aeronautical Products Division, Final report, contract 26-3425, 1978.

[12] Newstead, R.G. \& Lieskovsky, R.J., Air Tanker and Fire Retardant Drop Patterns. Northern Forest Research Centre, Canadian Forestry Service, Edmonton, 1985.

[13] Amorim, J.H., Numerical modelling of the aerial drop of firefighting agents by fixedwing aircraft. Part I: model development. Int J of Wildland Fire, 20, pp. 384-393, 2011. https://doi.org/10.1071/wf09122

[14] Hansen, R., Estimating the amount of water required to extinguish wildfires under different conditions and in various fuel types. Int $J$ of Wildland Fire, 21, pp. 525-536, 2012. https://doi.org/10.1071/wf11022

[15] Penney, G., Habibi, D., Cattani, M. \& Carter, M., Calculation of critical water flow rates for wildfire suppression. Fire 2019, 2, 3; doi:10.3390/fire2010003.

[16] Plucinski, M.P., Fighting flames and forging firelines: wildfire suppression effectiveness at the fire edge. Current Forestry Reports, 5, pp. 1-19, 2019. https://doi.org/10.1007/ s40725-019-00084-5

[17] Baum, H.R. \& McCaffrey, B.J., Fire induced flow field - theory and experiment. Fire Safety Science - Proceedings of the Second International Symposium, Tokyo, Japan, pp. 129-148, 1989.

[18] Tihay, V., Santoni P-A., Simeoni A., Garo J-P. \& Vantelon J-P., Skeletal and global mechanisms for the combustion of gases released by crushed forest fuels. Combust Flame, 156, pp. 1565-1575, 2009. https://doi.org/10.1016/j.combustflame.2009.05.004

[19] Heskestad, G., Fire plumes, flame heights, and air entrainment. In The SFPE Handbook of Fire Protection Engineering, fourth edition (eds: DiNenno P.J. et al.); NFPA, Quincy, 2008.

[20] McCaffrey, B.J., Purely buoyant diffusion flames: Some experimental results, national bureau of standards, NBSIR 79-1910, 1979. 
[21] Boysan, F., Ayers, W.H., Swithenbank, J., Pan Z., Three-Dimensional Model of Spray Combustion in Gas Turbine Combustors. Journal of Energy, 6, pp. 368-375, 1982. https://doi.org/10.2514/3.62618

[22] Link, E.D., The interaction of sprinkler sprays and fire plumes. Dissertation, University of Maryland, College Park, 2017.

[23] Van Meter, W.P., \& George, C.W., Correlating laboratory air drop data with retardant rheological properties. Research Paper INT-278, USDA, Ogden, 1981.

[24] Jain, M., Prakash, R.S., Tomar, G. \& Ravikrishna, R.V., Secondary breakup of a drop at moderate Weber numbers. Proc R Soc Lond, 471, 20140930, 2015. https://doi. org/10.1098/rspa.2014.0930

[25] Beyler, C.L., The interaction of fire and sprinklers. NBS GCR 77-105, National Bureau of Standards, Washington, DC, 1977.

[26] Hsiang, L.P. \& Faeth, G.M., Near-limit drop deformation and secondary breakup. Int J Multiphase Flow, 18, pp. 635-652, 1992. https://doi.org/10.1016/0301-9322(92)90036-g

[27] Turns, S.R., An Introduction to Combustion: Concepts and Applications, 2nd ed., McGraw-Hill, Singapore, 2000.

[28] Tamimi, A., Rinker, E.B. \& Sandall, O.C., Diffusion coefficients for hydrogen sulphide, carbon dioxide, and nitrous oxide in water over the temperature range 293-368 K. J Chem Eng Data, 39, pp. 330-332, 1994. https://doi.org/10.1021/je00014a031

[29] Andrews, P.L. \& Rothermel, R.C., Charts for interpreting wildland fire behavior characteristics. General Technical Report INT-131, USDA, Ogden, 1982.

[30] Loane, I.T. \& Gould, J.S., Aerial suppression of bushfires: cost-benefit study for Victoria. National Bushfire Research Unit, CSIRO Division of Forest Research, Canberra, 1986.

[31] Thomas, P.H., The size of flames from natural fires. Proceedings of the 9th International Symposium on Combustion, Ithaca, USA, 27 August-1 September 1963; The Combustion Institute: Pittsburgh, PA; pp. 844-859, 1963.

[32] Van Meter, W.P., Using Rheology to estimate short-term retardant droplet sizes. research Note INT-327, USDA, Ogden, 1983.

[33] Gould, J.S., Knight, I. \& Sullivan, A.L., Physical Modelling of Leaf Scorch Height from Prescribed Fires in Young Eucalyptus sieberi Regrowth Forests in South-eastern Australia. Int J of Wildland Fire, 7, pp. 7-20, 1997. https://doi.org/10.1071/wf9970007 